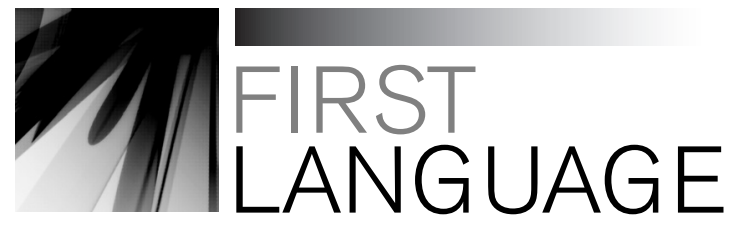

\title{
Conversational correlates of children's acquisition of mental verbs and a theory of mind
}

\author{
Alice Ann Howard, University of Connecticut \\ Lara Mayeux, University of Oklahoma \\ Letitia R. Naigles, University of Connecticut
}

\begin{abstract}
The purpose of this study was to conduct a detailed examination of the ways mothers use mental verbs in conversations with three- and four-year-old children, and to link these usages to the children's developing understanding of mental verbs and a theory of mind. Sixty three- and four-year-olds, either attending preschool (PS) or not (NPS) were given tasks assessing mental verb distinctions and false belief. Their mothers' mental verb use was coded for (a) frequency, (b) type of utterance, (c) type of subordinate clause, (d) the person of the subject of the verb, and (e) the certainty of think. Within the three-year-olds, the NPS children performed significantly better on the mental verb comprehension task; moreover, compared to the PS mothers, the NPS mothers were found to use: (1) less statements and more questions, (2) less first person utterances and more second person utterances, and (3) think in its 'very certain' form less often. In regression analyses, children's mental verb and false belief performance were positively predicted by maternal mental verb 1) questions, and 2) single clause utterances; the children's performance was negatively predicted by statements. These findings indicate how maternal input has the potential to promote or hinder children's understanding of the mind.
\end{abstract}




\section{KEYWORDS}

Language; maternal input; mental verbs; social-cognitive development; theory of mind

\section{INTRODUCTION}

Conversation has become increasingly recognized as crucial for children's development related to the mental world. For example, numerous chapters in Astington \& Baird (2005) discuss how conversation, both between peers and between children and their caregivers, can be revealing concerning the notion of a theory of mind (ToM); that is, that all people have minds and that what is in minds can differ between people and from reality (Wellman, 1990). One aspect of conversation the use of cognitive terms such as think - has been demonstrated to be particularly relevant because these terms: (a) provide labels for unseen relations (Adrian, Clemente \& Villanueva, 2005; Dunn \& Brophy, 2005; Furrow, Moore, Davidge \& Chiasson, 1992; Ruffman, Slade \& Crowe, 2002); (b) are sometimes presented in sentence complements which enable contrasts between matrix and subordinate clause truth values (J. deVilliers, 2005; P. deVilliers, 2005; Hale \& Tager-Flusberg, 2005); and/or (c) facilitate discussions in which differing points of view are contrasted (Dunn \& Brophy, 2005; Harris, 2005; Lohmann, Tomasello \& Meyer, 2005; Slaughter, Peterson \& Mackintosh, 2007).

In this paper, we continue this line of research, investigating in detail how caregiver use of mental verbs might help children to learn about the mental world. We target children's acquisition of mental verbs such as think, guess and know as our primary dependent variables. Because these are arbitrary linguistic symbols for specific mental states and processes, they must be acquired from specific way(s) that caregivers and others use them in conversation. Whereas most investigations of the roles of mental state talk in ToM development have combined the uses of many different mental verbs, we will investigate how specific uses of specific mental verbs might help children learn these verbs - and, to the extent that mental verbs (MV) and ToM share antecedents, how they develop a ToM as well.

\section{Challenges to children's mental verb acquisition}

Mental verbs are challenging for children to learn for a number of reasons. First, MVs are not common in either adult or child spontaneous speech; they are produced only in about $10 \%$ of utterances across languages and contexts and so represent relatively little of any given child's input (Adrian et al., 2007; Furrow et al., 1992; Slaughter et al., 2007; Tardif \& Wellman, 2000). Second, MVs refer to intangible relations and processes, difficult to glean from the visuo-spatial scene (Gleitman, 1990; Gleitman, Cassidy \& Nappa, 2005; Montgomery, 2002). Third, mental verbs may have a number of different semantic senses, and distinguishing these in the input is not transparent (Naigles, 2000; see also Booth, Hall, Robison \& Kim, 1997). For example, know may be used to indicate certainty ('I know that it's sunny outside'), shared information ('You know, it's almost time to leave'), or 
communication ('Let me know if you want some help with that'), whereas think typically describes processes ('I'm thinking about alligators') or uncertain states ('I think it's raining outside'). However, think also includes a 'comment clause' sense which is used to indicate certainty, particularly in the speech of adults to children ('I think it's time for your nap'; Manson, 1995; Naigles, 2000; Urmson, 1952). Thus, distinguishing between think's 'canonical' uncertain sense and 'comment' certain sense presents a challenge for the young mental verb learner.

Probably because of such challenges, children's development of MVs begins later than that of concrete verbs, and has a longer trajectory. Know emerges first, but only in its conversational use ('know what?'), by 28 months of age; references to actual mental states develop around three years of age (Bartsch \& Wellman, 1995; Furrow et al., 1992; Shatz, Wellman \& Silber, 1983). Around four years of age, children begin using MVs more distinctively both in production and comprehension (Frank \& Hall, 1991; Moore, Bryant \& Furrow, 1989). For example, Moore et al. (1989) found that among children aged three to eight, three-year-olds performed at chance in distinguishing know as more certain than think whereas four-year-olds performed above chance (albeit not perfectly). It was not until the children were eight years of age that they correctly distinguished think as more certain than guess (see also Moore \& Davidge, 1989). Indeed, mental verb understanding continues to develop into grade school, with seven- to nine-year-olds understanding more of the plethora of know senses and further distinguishing think and know on information processing dimensions (Booth \& Hall, 1995; Schwanenflugel, Fabricius \& Noyes, 1996).

\section{Environmental influences on MV development}

Thus far, the predominant aspect of conversations that has been demonstrated to influence children's mental verb acquisition is maternal frequency of use. On a general level, mothers use more desire terms than belief terms when their children are two-years-old, but steadily increase their frequency of use of belief terms over the course of the next year, mirroring the children's increased use (Beeghly, Bretherton \& Mervis, 1986; Brown \& Dunn, 1991; Moore, Furrow, Chiasson \& Patriquin, 1994; Jenkins, Turrell, Kogushi, Lollis \& Ross, 2003). More specifically, mothers' frequency of use of belief words when their children were two years of age predicted the children's frequency of use at the ages of two, three, and four years, as well as their mental verb comprehension at age four (Jenkins et al., 2003; Moore et al., 1994), and mothers' use of mental terms for true mental reference when children were age two predicted the children's use of such words in these same functions when they were age three (Furrow et al., 1992). Relatedly, Ruffman et al. (2002) have reported that mothers' frequency of mental state utterances was a strong predictor of their children's theory of mind performance across the age range of three to five years.

These findings from prior studies of maternal-child conversations suggest that children's development of mental state verbs, and thus (at least partially) a theory of mind, is fostered by the frequency of maternal mental verb utterances. The question arises, however, whether frequency of use is the only (or even major) influence. Recall that Furrow et al. (1992) found some preliminary evidence that the way(s) the mothers used the verbs were reflected in their children's subsequent uses. In this paper, we 
investigate this possibility in more detail, considering a variety of ways that mothers might use mental verbs in conversations. In particular, we will investigate maternal use of mental verbs: (a) to refer to self versus other, (b) capturing certain versus uncertain senses, (c) in different types of subordinate clauses, and (d) in questions versus statements. We address each of these components of mental verbs below.

Booth et al. (1997) hypothesized that uses of know to refer to others would promote advances in MV use via an understanding of different perspectives. Indeed, the parents of four children from the CHILDES database (MacWhinney \& Snow, 1985) used know equivalently in self and other references when their children were 27-45 months of age, but then used know more to refer to others when their children were 51-57 months of age, mirroring their children's use of know more in reference to themselves during the earlier period and more in reference to others during the later period. The parents' shift in usage may have simply primed the children's, as both were drawn from the same conversations; however, Adrian et al. (2007) showed that mothers who used MVs more in reference to their children, and to characters in a storybook, had children who subsequently performed better on a battery of mental state understanding tasks. We will further address this hypothesis in the current study.

As discussed above, the verb think can be used in both a 'canonical' uncertain sense and a 'comment' certain sense. Frequent uses of the 'comment' certain sense have the potential to hinder or at least slow down children's development of the certainty distinction between think and know. Naigles (2000) reported a smallscale study in which children viewed a television show that included many instances of the 'comment' sense of think; those children performed more poorly than nonviewing controls on tests of mental verb understanding. In this study, we will compare how children whose everyday conversations include greater versus fewer 'comment' uses of think perform on such mental verb tasks.

Parental use of modal auxiliaries (e.g., might, must, could, should) might also play a role in children's understanding of mental verbs, as these modals describe how the speaker evaluates her message (Shatz \& Wilcox, 1991). Especially, mothers who use mental verb utterances containing modal auxiliaries may more effectively communicate their own mental state to their children, in that they are providing additional information concerning their own degree of certainty about the likelihood of the proposition (compare 'I think we should go outside' with 'I think it's time to go outside'). In this study, we examine whether maternal uses of subjunctive clauses, which contain these modal auxiliaries, might aid in children's acquisition of the certainty distinctions among mental verbs as well as their understanding of mental representations in general.

An additional aspect of parental conversations that might influence children's acquisition of mental verbs is utterance type; specifically, the use of questions versus statements or directives. Questions may provide specific assistance in MV acquisition because they are the medium by which children's thoughts and perspectives can be highlighted or made the topic of discussion (e.g., Dunn \& Brophy, 2005). Indeed, Adrian et al. (2007) have reported that maternal use of cognitive verbs in question format significantly predicted subsequent overall mental state understanding; however, both they and Slaughter et al. (2007) report that certain kinds 
of mental verb statements (i.e., cognitive clarifications) also seem facilitative. In this study, we investigated how children's performance on MV tasks relates to their mothers' uses of MVs in different utterance types.

\section{Summary and prospectus}

The purpose of this study was to conduct a detailed examination of the ways mothers use mental verbs in conversations with three- and four-year-old children, and to link these usages to the children's developing understanding of mental verbs and a theory of mind. Given that MVs comprise such a small percentage of the utterances in spontaneous conversation (less than 10\%), we sought an additional manipulation to increase the variation of the sample and thus the likelihood of finding significant effects. Previous research has reported that children's understanding of MVs and/or a ToM varies by the amount of schooling they have had (e.g., Naigles, 2000; Vinden, 2002); however, these studies may have confounded schooling and SES, which also seems to have an effect (Shatz, Diesendruck, Martinez-Beck \& Akar, 2003). Because most North American samples include only children attending preschool, we were interested in whether children at a given socio-economic level, either attending preschool or not, might vary in their MV and/or ToM understanding. And because the decision to send a three- or four-year-old to preschool (or not) is a choice (within the upper-middle SES) that reflects differences in parenting philosophy, parents who make different decisions are likely also to vary in relevant aspects of their conversations with their children (Dunn \& Brown, 1991; Hohenstein, Naigles \& Marsland, 1998; Rogoff, Mistry, Goncu \& Mosier, 1991).

Thus, in this study we tested two groups of children: those who attended preschool or daycare for at least three hours per week, and those who did not attend any preschool or daycare. The children were given a battery of tasks assessing MV understanding, ToM development and general language abilities; all were tested at home. The children were also videotaped for 30 minutes while interacting with their mothers; these interactions provided the data to analyze maternal input. The focus of the present study concerns the mothers' conversations with their children and, specifically, how differences between the two groups of mothers (i.e., those whose children do vs. do not attend preschool) may account for the variation in mental verb understanding of the children. We hypothesized that children's mental verb understanding and false belief performance would be positively related to higher frequencies of maternal mental verb utterances (a) promoting varied thoughts and perspectives, (b) containing modal auxiliaries, (c) referring to others, and (d) including 'uncertain' rather than 'certain' uses of think.

\section{METHOD}

\section{Participants}

Sixty children (32 three-year-olds, 28 four-year-olds) and their mothers were recruited for participation in the study through preschools and library story hours in 
northeastern Connecticut, USA. The final sample consisted of 16 three-year-old preschool attendees ( 8 girls, 8 boys; $M$ age 3.7 years, $S D=0.21$ ), 16 three-year-old preschool non-attendees (9 girls, 7 boys; $M$ age $=3.5$ years, $S D=0.33$ ), 16 fouryear-old preschool attendees ( 9 girls, 7 boys; $M$ age $=4.5$ years, $S D=0.36$ ), and 12 four-year-old preschool non-attendees ( 6 girls, 6 boys; $M$ age 4.4 years, SD = 0.34). The majority of the children were from White, middle- to upper-class suburban or rural homes in northeastern Connecticut. The amount of time that the preschool-attending children (PS) spent in the classroom ranged from 3 to 45 hours per week ( $M=20.5$ hours, $S D=16.4$ hours). The non-attending preschool children (NPS) were not enrolled in any conventional preschool or daycare program. All the children were native speakers of American English.

\section{Materials}

The children were administered the Test for Auditory Comprehension of Language (TACL-3; Carrow-Woolfolk,1999), which included subsections on vocabulary, grammatical morphemes and elaborated phrases and sentences. The TACL-3 has been normed including ethnic majority, minority and language-impaired samples, validated against other standardized tests for good item discrimination, and shown to be reliable across time both within and across subsections (Carrow-Woolfolk, 1999). For each item, the child was presented with three pictures, one of which corresponded to a spoken stimulus. The child was then asked to point to the picture that represented the spoken stimulus. Administration proceeded until the child chose an incorrect picture on three consecutive trials.

Two mental verb tasks and two theory-of-mind tasks were administered in a counterbalanced order. An adaptation of Moore et al. (1989) was used to assess the child's understanding of the certainty distinctions between think, know and guess. In this 'puppet show' game, the child was presented with two different colored boxes and was told that a sticker was hidden in one of them. Two puppets, Jazz (a cow) and George (a cat), each gave the child different clues as to the location of a hidden sticker, distinguishing think, know and guess. For example:

Jazz says: 'I think it's in the blue box.'

George says: 'I know it's in the yellow box.'

The child was then asked to identify the box that they believed contained the sticker.

To confirm that the child understood the rules of the game, three practice trials were administered. The clues in the practice trials were based only on negation (e.g., 'it's in the blue box' or 'it's not in the yellow box'). All children passed at least one of each valence of the practice trials; most passed all three. The 12 test trials (4 items for each of the pairwise comparisons of think, know and guess) followed. The trials were counterbalanced for order of verb pair, color of correct box, speaker (Jazz or George), and whether the correct box was designated in the first or second clue. After the child indicated the box in which he/she believed the sticker to be, 
the chosen box was set aside to rule out any reinforcement of a particular box color or puppet. Only the child's answers to the eight comparisons of think-know and know-guess were analyzed, as previous studies have shown that children under eight years of age do not reliably distinguish between think and guess (Moore et al., 1989). Therefore, the puppet task yielded a possible score of zero to eight, with one point given for each correctly chosen box.

The second task assessing mental verb understanding involved stickers hidden around a toy Noah's ark set (Tager-Flusberg, 2000). The child was told that Noah and Sarah had hidden their stickers around their ark, but they could not remember who hid their stickers in which places. The experimenter revealed each sticker's hiding place, and Noah and Sarah then gave clues as to which of them had hidden the sticker in that particular place. For example:

Noah says: 'I think I hid my sticker next to the ark.'

Sarah says: 'I know I hid my sticker next to the ark.'

The child was then asked to point to the doll that he believed had hidden the sticker. The trials were counterbalanced for verb, order of speaker, and level of certainty each doll indicated.

As with the puppet task, three practice trials and 12 test trials were given. The key difference between the hiding task and the puppet show task was the manner in which the clues were given. In the hiding task, the sticker is identified and the unknown is who hid it, whereas in the puppet task, the sticker is hidden and the unknown is where it is. The hiding task was scored in the same manner as the puppet task, in that the trials containing guess were omitted, yielding a possible final score of zero to eight.

Two standard false-belief tasks assessed the children's theory of mind: an unexpected contents task and a change-of-location task. In the unexpected contents task (Perner, Leekam \& Wimmer, 1987) the child was first presented with an opaque BandAid box, which actually contained balloons. The child was asked, 'What do you think is inside here?' After his/her response, the child was shown the actual contents of the box. The box was then closed and the child was asked, 'What is really inside of this?' The two test questions were then administered, which consisted of asking the child: (1) 'What did you think was in this box before we opened it?' and (2) 'What would your friend $X$ think was in the box if we showed it to him/her?' The child was given one point for each correct answer, resulting in a possible score of $0-2$. In the changeof-location task (Wimmer \& Perner, 1983), the child was introduced to Astro, a cow puppet, and was told Astro wanted to play a new game. Astro told the children that she would be taking a trip soon and needed to pack her toy monkey in her blue suitcase, represented by a blue box. After putting the monkey inside the box, Astro left for the grocery store. After reassuring the children that Astro was gone, the experimenter asked the children to play a trick on Astro by moving the monkey from the blue box to the white box. Afterwards, the children were asked: 'When Astro gets back, where will she look for the monkey?', and 'Do you remember where Astro put the monkey before he left?' This task was also scored 0-2. 


\section{Demographic information}

During testing, the mother filled out a questionnaire regarding her and her husband's educational level, the number and ages of siblings, the number of hours spent in daycare or preschool, the number of hours spent reading with her child, and how many hours of television the child watched per week. The socio-economic status was calculated using Hollingshead's two-factor Index of Social Position (ISP; Hollingshead, 1971). No significant differences were found between the PS and NPS children on any of these demographic variables. Furthermore, no significant differences were found between the three- and four-year-old PS children in the number of hours spent in daycare or preschool.

\section{Procedure}

The child participants engaged in 30 minutes of naturalistic interaction with their mothers before being administered the experimental tasks in counterbalanced order. The context of the interaction varied widely, including mealtime, cooking, arts and crafts, or toy play. However, in order to provide a similar context for each dyad, as well as to help to elicit mental verb usage, each mother-child pair was asked to play a memory game that involved finding matching sets of cards. Most of the dyads played this game for an average of five minutes.

The TACL-3 was then administered to each child. The remaining tasks (i.e., the mental verb and false belief tasks) were presented in a counterbalanced order. The child's parents were permitted to remain during testing, but they were prohibited from making comments directly relating to the tasks. Testing for each child lasted approximately 20 to 30 minutes.

\section{Coding of interactions}

The mother-child interactions were first transcribed. Due to missing videos from three children (three-year-old PS children), only 57 of the original 60 children were included. After transcription, utterances containing the five most frequent mental verbs, which were think, know, remember, guess and forget, were extracted. Other mental verbs (e.g., pretend, understand) appeared fewer than 5 times across all transcripts. These remaining utterances were then coded for: (a) frequency, (b) type of utterance (i.e., wh-question, $\mathrm{y} / \mathrm{n}$-question, statement, or directive), (c) presence and mood of subordinate clause (i.e., subjunctive clause, finite clause, or no clause), (d) the person of the subject of the verb (i.e., first, second or third person), and (e) semantics (i.e., certainty of think). These coding schemes are described in more detail below.

\section{Overall frequency}

The frequency of mental verb utterances produced by each mother and child was tabulated. However, to compare the mental verb input frequency of the mothers of PS and NPS children, the relative amount of overall speech needed to be controlled. Therefore, when calculating a mother's mean frequency of each mental verb, the number of times she used that verb was divided by her total number of utterances 
throughout the 30 minutes of interaction. Subsequently, the mean frequency of each mental verb was calculated for the group as a whole (i.e., mothers of PS children and mothers of NPS children). Table 1 presents the mothers' mean frequency for each mental verb by age and preschool status of their children. Given that the mothers of the three-year-old NPS children produced significantly more utterances than the other three groups, percentages rather than raw frequencies of mental verb use are displayed and analyzed.

A repeated measures ANOVA (Age $x$ Preschool $x$ Verb) yielded a significant effect of mental verb $(F(4,171)=62.78, p<0.001)$. Post-hoc $t$-tests using a Bonferroni correction of alpha levels revealed that think (4.95\%) and know (5.07\%) were produced significantly more than remember $(2.81 \%)(t s(56)>4.61$, ps $<0.001)$, which was produced significantly more than forget $(0.43 \%)$ and guess $(0.26 \%)(t s(56)=$ 6.42 , ps $<0.001)$. No interactions between verb, age or preschool status of the child were significant. Because forget and guess comprised such a small percentage of the maternal mental verb uses, these were not analyzed further.

\section{Utterance type}

Each utterance containing think, know or remember was coded as one of four types: wh-question, yes/no-question, statement, or directive/imperative; examples are given in Table 2 .

\section{Subordinate clause type}

Each think, know and remember utterance was also parsed according to syntactic frame. These utterances were then coded for the type of subordinate clause it contained, if any. The four types of clauses were 'diagnosed' by the type of auxiliary, as

Table 1 Maternal input frequency of mental verbs: percentage means and (in brackets) standard deviations

\begin{tabular}{lccccccc}
\hline & $N$ & Think & Know & Remember & Guess & Forget & Total utts $^{a}$ \\
\hline 3-year-olds & & & & & & & \\
PS mothers & 13 & 4.75 & 5.37 & 1.84 & 0.69 & 0.36 & 2685 \\
& & $(4.20)$ & $(5.32)$ & $(2.27)$ & $(1.08)$ & $(0.47)$ & \\
NPS mothers & 16 & 4.58 & 3.38 & 2.50 & 0.35 & 0.21 & 4836 \\
& & $(3.18)$ & $(2.17)$ & $(2.23)$ & $(0.64)$ & $(0.26)$ & \\
4-year-olds & & & & & & & \\
PS mothers & 16 & 5.45 & 6.45 & 3.81 & 0.42 & 0.24 & 3181 \\
& & $(2.87)$ & $(3.13)$ & $(4.04)$ & $(0.37)$ & $(0.53)$ & \\
NPS mothers & 12 & 5.05 & 5.40 & 3.18 & 0.30 & 0.21 & 2613 \\
& & $(2.39)$ & $(2.73)$ & $(2.76)$ & $(0.44)$ & $(0.35)$ & \\
\hline
\end{tabular}

Note. Means are the average of the percentage score for each mother. The percentage score was calculated by dividing the number of occurrences of each verb (e.g., think, know, etc.) per mother by the total number of utterances for the mother.

a Total number of utterances for the group. 
Table 2 Coding of maternal utterances

\begin{tabular}{|c|c|c|}
\hline Category & Subcategory & Example \\
\hline \multirow[t]{4}{*}{ Utterance } & Wh-question & What do you think? / Who knows what this is? \\
\hline & Yes/no-question & $\begin{array}{l}\text { Do you know what this is? / Remember } \\
\text { this? }\end{array}$ \\
\hline & Statement & I remember where it is. / I know that song. \\
\hline & Directive/imperative & Think about it. / Remember where you put it. \\
\hline \multirow[t]{4}{*}{ Subordinate clause } & Subjunctive & What do you think we should do? \\
\hline & Tensed & Didn't you know he was in the room? \\
\hline & No clause & I don't know. \\
\hline & Miscellaneous & You know how to play this. \\
\hline \multirow[t]{5}{*}{ Certainty } & Very certain & $\begin{array}{l}\text { Very assertive tone while teaching, guiding, } \\
\text { or correcting child with the intent of letting } \\
\text { the child know what is expected of him (e.g., } \\
\text { I think you should try and finish one game, } \\
\text { and then play with him, cause he's a big kid.) }\end{array}$ \\
\hline & Certain & $\begin{array}{l}\text { Laughing yet correcting, or giving child } \\
\text { instructions in an upbeat tone (e.g., [giggle] I } \\
\text { don't think you'll be working on the roof.). } \\
\text { Also included utterances in which the mother } \\
\text { doesn't sound entirely certain of what she's } \\
\text { saying, but her utterance is backed up by } \\
\text { action (e.g., I think I forgot to shut Caitlin's } \\
\text { door. [can hear Caitlin crying down the hall]). }\end{array}$ \\
\hline & Ambiguous & $\begin{array}{l}\text { Utterances that were unable to be classified } \\
\text { into one of the four categories }(0-7 \% \text { across } \\
\text { groups). }\end{array}$ \\
\hline & Uncertain & $\begin{array}{l}\text { Stating an opinion or belief that is, or could } \\
\text { be, contradicted (e.g., [in reference to } \\
\text { jaguars] I think they live in the jungle, we } \\
\text { need to look that up.). }\end{array}$ \\
\hline & Very uncertain & $\begin{array}{l}\text { Very unsure tone, emphasizing the word } \\
\text { think, pausing mid-sentence to reflect on } \\
\text { statement (e.g., I thought the piece was } \\
\text { here for the giraffe, and I...oh, I see over } \\
\text { here, I'm sorry...). These statements were } \\
\text { also commonly followed by 'I don't know,' } \\
\text { or contrasted with what the mother did } \\
\text { know (e.g., They are an animal that live } \\
\text { in...I think they live in Africa, they run really } \\
\text { fast, I know that.) }\end{array}$ \\
\hline
\end{tabular}


follows (see Table 2 for examples): (a) subjunctive clause, containing modal auxiliaries such as should, could, would, might, etc., (b) tensed clause, containing a tensed or finite verb, (c) no clause, and (d) miscellaneous, which included all utterances that could not be classified in the first three categories (e.g., a subordinate clause containing an infinitive, a sentence in which the mother trails off before finishing her thought, etc.; $N=42$ across all groups).

\section{Person}

The person of each maternal think, know and remember utterance was also coded. The utterance was coded as 'first person' if the mother referred to herself or to a group including herself (e.g., I, we). The utterance was coded as 'second person' if the mother referred to her child (e.g., you), and the utterance was coded as 'third person' if the mother referred to other people, animals, things, etc. (e.g., he, she, it, they).

\section{Certainty}

The certainty of the verb think, or whether the mother used think in its 'certain' or 'uncertain' sense, was also coded. Only think utterances classified as 'statements' were coded for level of certainty because the degree of certainty in questions is difficult to assess. The mere fact a question is asked may make a verb more uncertain. Therefore, wh-questions, $y / n$-questions and directives were excluded. The total number of think utterances that were coded on this parameter resulted in: 106 out of 220 total think utterances (48\%) for the three-year-old NPS mothers, 73 out of 126 total think utterances (58\%) for the three-year-old PS mothers, 87 out of 147 total think utterances (59\%) for the four-year-old NPS mothers, and 102 out of 169 total think utterances (60\%) for the four-year-old PS mothers. Thus, approximately half of all think utterances were coded for certainty. The coding scheme used to determine the certainty level of think ranged from 1 to 5 , with 1 designating think as 'very certain,' and 5 distinguishing think as 'very uncertain'. Descriptions of the five categories are listed in Table 2. Another researcher, blind to the hypothesis, coded all the target think utterances for level of certainty. Inter-rater reliability between the two coders was at first $85 \%$. Discussion followed until the remaining $15 \%$ was agreed upon.

\section{RESULTS}

The results are organized into three sections, covering (a) the children's performance on the mental verb and false belief tasks, (b) the group comparisons of the maternal uses of mental verbs, and (c) the regressions investigating the degree to which specific aspects of maternal mental verb use predict children's individual performances.

\section{Child mental verb and false belief performance}

Mean scores for each group on the two mental verb tasks and two false belief tasks can be found in Table 3. The four-year-olds performed significantly above chance on the two mental verb tasks combined $(t(27)=4.66, p<0.001)$, while the 
three-year-olds performed at chance $(t(31)=0.99, n s)$. On the two false belief tasks combined, the four-year-olds performed above chance $(t(27)=2.68, p<0.05)$, while the three-year-olds approached significance in performing below chance $(t(31)=-1.98, p<0.06)$. Three Age $x$ Preschool ANOVAs compared the children's performance on (1) the puppet mental verb task, (2) the hiding mental verb task, and (3) the two mental verb tasks combined. For all three analyses, an age effect emerged in that the four-year-olds scored significantly higher on the puppet and hiding mental verb tasks alone, as well as on the two mental verb tasks combined $\left(F(1,56)=6.21, p<0.05\right.$ (partial $\left.\eta^{2}=0.10\right) ; F(1,56)=5.99, p<0.05$ (partial $\left.\eta^{2}=0.10\right) ; F(1,56)=10.40, p<0.01$ (partial $\eta^{2}=0.16$ ), respectively). Although no interactions with preschool were found, exploratory $t$-tests revealed that, among the three-year-olds, the NPS children performed significantly higher on the puppet task than the PS children $(t(30)=2.09, p<0.05)$, thus demonstrating variance among the PS and NPS children that might be related to variance in the maternal speech. Three Age x Preschool ANOVAs further compared the children's performance on (1) the unexpected contents task, (2) the unexpected location task, and (3) the two tasks combined. No effects appeared for the unexpected contents task; however, the four-year-olds performed significantly higher on the unexpected location task $\left(F(1,56)=13.10, p<0.01\right.$, partial $\left.\eta^{2}=0.19\right)$, and the preschool children tended to perform higher on the same task $(F(1,56)=3.99, p<0.052$, partial $\left.\eta^{2}=0.07\right)$. For the two tasks combined, only an age effect appeared, in that the four-year-olds performed significantly higher on both the tasks combined $\left(F(1,56)=10.16, p<0.01\right.$, partial $\left.\eta^{2}=0.15\right)$. With regard to the TACL scores (see Table 4), four-year-olds again performed at a significantly higher level than three-year-olds $\left(F(1,56)=29.81, p<0.001\right.$, partial $\left.\eta^{2}=0.35\right)$.

Correlational analyses using the mental verb task scores, false belief task scores, and the scores from the TACL-3 for all groups combined are presented in Table 5. As

Table 3 Means and (in brackets) standard deviations of scores on mental verb understanding and false belief tasks

\begin{tabular}{lccccc}
\hline & $N$ & Puppet $^{1}$ & Hiding $^{1}$ & $U L^{2 a}$ & $U C^{2 b}$ \\
\hline $\begin{array}{l}\text { 3-year-olds } \\
\text { PS }\end{array}$ & & & & & \\
& 16 & 3.75 & 4.06 & 1.06 & 0.69 \\
NPS & & $(0.93)$ & $(1.95)$ & $(0.68)$ & $(0.70)$ \\
& 16 & 4.69 & 4.44 & 0.81 & 0.63 \\
4-year-olds & & $(1.54)$ & $(1.63)$ & $(0.66)$ & $(0.89)$ \\
PS & & & & & \\
& 16 & 5.50 & 5.06 & 1.75 & 1.06 \\
NPS & 12 & $(1.79)$ & $(1.57)$ & $(0.45)$ & $(0.68)$ \\
& & 5.08 & 5.58 & 1.33 & 1.00 \\
& & $(2.27)$ & $(1.51)$ & $(0.78)$ & $(0.85)$ \\
\hline
\end{tabular}

1 out of a possible $8 ;{ }^{2}$ out of a possible 2

${ }^{a}$ unexpected location task; ${ }^{b}$ unexpected contents task 
the table shows, the scores from the two mental verb tasks were significantly correlated, as were the scores from the two false belief tasks. Moreover, the children's score from a combination of both of the mental verb tasks was significantly related to children's performance on both of the false belief tasks combined. Finally, the children's raw scores from the language comprehension measure were significantly associated with scores from the puppet task as well as with both false belief tasks.

Table 4 Means and (in brackets) standard deviations of raw scores on the Test for Auditory Comprehension of Language (TACL-3)

\begin{tabular}{lccccc}
\hline & $N$ & Vocabulary & Morphemes & $\begin{array}{c}\text { Elaborated } \\
\text { sentences }\end{array}$ & Total TACL \\
\hline $\begin{array}{l}\text { 3-year-olds } \\
\text { PS }\end{array}$ & 16 & 23.44 & 16.50 & 12.19 & 51.56 \\
& & $(4.87)$ & $(7.14)$ & $(5.36)$ & $(17.06)$ \\
NPS & 16 & 21.75 & 13.13 & 13.00 & 46.75 \\
& & $(7.10)$ & $(5.50)$ & $(7.52)$ & $(15.96)$ \\
4-year-olds & & & & & \\
PS & 16 & $33.31^{*}$ & 21.56 & 20.63 & 75.81 \\
& & $(4.03)$ & $(8.88)$ & $(9.89)$ & $(19.97)$ \\
NPS & 12 & $29.58^{*}$ & 20.33 & 18.00 & 68.25 \\
& & $(5.62)$ & $(4.87)$ & $(8.07)$ & $(12.61)$ \\
\hline
\end{tabular}

${ }^{*} p<0.052$.

Table 5 Means, standard deviations and correlations among age, mental verb understanding and false belief tasks $(N=60)$

\begin{tabular}{|c|c|c|c|c|c|c|c|c|c|c|}
\hline & 1 & 2 & 3 & 4 & 5 & 6 & 7 & $N$ & $M$ & $S D$ \\
\hline 1. Age & - & & & & & & & 60 & 4.00 & 0.54 \\
\hline 2. TACL & $0.68^{* *}$ & - & & & & & & 60 & 60.08 & 19.87 \\
\hline 3. MV $1^{\mathrm{a}}$ & $0.33^{*}$ & $0.27^{* *}$ & - & & & & & 60 & 4.73 & 1.75 \\
\hline 4. $M V 2^{b}$ & $0.26 *$ & $0.24^{+}$ & $0.37^{* *}$ & - & & & & 60 & 4.73 & 1.74 \\
\hline 5. MVUc & $0.38^{*}$ & $0.31 *$ & $0.83^{* *}$ & $0.82 * *$ & - & & & 60 & 9.43 & 2.84 \\
\hline 6. UCd & 0.21 & $0.28 *$ & $0.25^{+}$ & 0.18 & $0.25^{+}$ & - & & 60 & 0.83 & 0.78 \\
\hline 7. $U L^{e}$ & $0.51^{* *}$ & $0.54^{* *}$ & $0.31 *$ & 0.19 & $0.32 *$ & $0.43^{* *}$ & - & 60 & 1.23 & 0.72 \\
\hline 8. $\mathrm{FB}^{f}$ & $0.42 * *$ & $0.48^{* *}$ & $0.33^{*}$ & 0.22 & $0.32 *$ & $0.86^{* *}$ & $0.83^{* *}$ & 60 & 2.07 & 1.27 \\
\hline
\end{tabular}

$+p<0.07 ;{ }^{*} p<0.05 ;{ }^{*} p<0.01$

a puppet task (scored $0-8$ ); ${ }^{b}$ hiding task (scored $0-8$ ); ${ }^{c}$ total mental verb understanding score (scored 0-16); ${ }^{\mathrm{d}}$ unexpected contents task (scored 0-2); ${ }^{\mathrm{e}}$ unexpected location task (scored 0-2);

${ }^{f}$ total false belief score (scored $\left.0-4\right)$ 


\section{Maternal conversations}

These analyses compared the mothers of three- and four-year-old PS and NPS children on the basis of their mental verb use in different types of utterances, in different types of subordinate clauses, with different persons as the subjects, and with different degrees of certainty.

\section{Analysis strategy}

Because the MVs comprised such a small percentage of the mothers' total utterances, we analyzed maternal usage of MVs out of their total mental verb use (see Table 1). Maternal think, know and remember uses are thus presented as percentages of total mental verb utterances (because forget and guess are included in the total, think, know and remember percentages do not sum to 100). Finally, because our data did not fully satisfy the assumptions of the independent tests (i.e., normal distribution or homogeneity-of-variance), we also performed Mann-Whitney $U$ tests, which use rank order to evaluate two populations. These non-parametric analyses allowed us to compare the PS versus the NPS groups directly (Gravetter \& Wallnau, 2004). Overall, the non-parametric tests corroborated the main analyses; in a few cases, they extended the parametric findings and are presented in footnotes.

\section{Parametric analyses}

The parametric analyses examined the effects of age and preschool status of the child (between-subjects) as well as the effects of utterance type, clause type and person on maternal percentage of think, know and remember uses (withinsubjects). Three-way ANOVAs were performed within each input category, one each for think uses, know uses and remember uses. For all analyses, the Bonferroni alpha correction was used to examine subsequent multiple comparisons upon the emergence of a main effect and/or an interaction effect.

\section{Utterance type}

A Preschool $x$ Age $x$ Utterance type repeated measures ANOVA was first performed with the verb think. Only a significant effect of utterance type was found $(F(3$, $159)=110.96, p<0.001$, partial $\eta^{2}=0.68$ ). A significantly higher percentage of think utterances appeared in the form of statements $(26.4 \%)$ than wh-questions $(4.6 \% ; t(56)=10.34, p<0.001)$ or yes/no-questions $(5.9 \% ; t(56)=10.25$, $p<0.001)$. Both types of questions appeared at significantly higher percentages than directives $(0.3 \% ; t(56)=5.49, p<0.001 ; t(56)=6.82, p<0.001$, respectively).

A second repeated-measures ANOVA was performed with the verb know. A significant main effect of utterance type emerged $(F(3,159)=84.49, p<0.001$, partial $\left.\eta^{2}=0.86\right)$. Statements containing know were produced at significantly higher percentages than yes/no-questions containing know (23\% vs. $14 \%$; $t(56)=3.51$, $p<0.01)$. Moreover, yes/no-questions with know appeared at significantly higher percentages than wh-questions $(1 \% ; t(56)=7.41, p<0.001)$, which appeared at significantly higher percentages than directives $(0.2 \% ; t(56)=3.17, p<0.001)$. A significant Preschool $\times$ Age $\times$ Utterance type interaction also emerged $(F(3,159)=$ $4.65 p<0.01$, partial $\eta^{2}=0.15$ ). Among the three-year-olds, the PS children heard a significantly higher percentage of statements with know than the NPS children did 
$(t(27)=-2.76, p<0.05)$. No significant differences were found between the NPS and PS mothers of the four-year-olds.

A third repeated-measures ANOVA was performed with the verb remember. A main effect of utterance type emerged $(F(3,159)=43.16, p<0.001$, partial $\eta^{2}=0.72$ ), demonstrating that remember appeared at significantly higher percentages in the form of yes/no-questions compared with statements (11\% vs. 7\%; $t(56)=-2.49, p<0.05)$, which, in turn, appeared at significantly higher percentages than directives and wh-questions $(t(56)=5.31, p<0.001 ; t(56)=5.84$, $p<0.001)$. A significant Preschool $\times$ Utterance type interaction also emerged $\left(F(3,159)=4.34, p<0.01\right.$, partial $\left.\eta^{2}=0.17\right)$, indicating that the NPS mothers overall used a significantly higher percentage of yes/no-questions with remember than the PS mothers did $(t(55)=2.59, p<0.05){ }_{i}^{1}$ see Fig. 1 .

\section{Subordinate clause type}

Three repeated-measures ANOVAs examined the frequency with which think, know and remember occurred in the input relative to the children's preschool status, age and maternal subordinate clause type (Preschool $x$ Age $x$ Clause Type). For the verb think, only the main effect of subordinate clause type emerged $(F(3,159)=156.39$, $p<0.001$, partial $\eta^{2}=0.86$ ), in that mothers used think at significantly higher percentages with a finite clause than utterances without a subordinate clause at all $(27.7 \%$ vs. $6.77 \% ; t(56)=11.34, p<0.001)$, which appeared significantly less often than those with a subjunctive clause $(2.3 \% ; t(56)=-4.62, p<0.001)$. Similar results were found for the verb know. There was a main effect of subordinate clause type $\left(F(3,159)=85.80, p<0.001\right.$, partial $\left.\eta^{2}=0.85\right)$, such that know utterances with a finite subordinate clause or no subordinate clause appeared at significantly higher percentages than utterances with a subjunctive clause $(t(56)=-12.41$, $p<0.001, t(56)=-12.57, p<0.001$, respectively). A main effect of subordinate clause type was also found for remember $\left(F(3,159)=50.64, p<0.001\right.$, partial $\eta^{2}=$ 0.69 ), in that remember utterances with a finite subordinate clause or no subordinate clause appeared at significantly higher percentages than utterances with a subjunctive clause $(t(56)=-8.60, p<0.001 ; t(56)=-8.98, p<0.001$, respectively).

\section{Person}

For the verb think, a repeated measures ANOVA (Age $\times$ Preschool $\times$ Person) revealed a significant main effect of person $\left(F(2,106)=70.96, p<0.001\right.$, partial $\left.\eta^{2}=0.83\right)$. Think appeared at significantly higher percentages in the form of first person $(24.7 \%)$ than second person (11.8\%), which, in turn, appeared at significantly higher percentages than third person $(0.7 \% ; t(56)=5.19, p<0.001 ; t(56)=8.42$, $p<0.001$, respectively). For the verb know, a main effect of person again emerged $\left(F(2,106)=37.69, p<0.001\right.$, partial $\left.\eta^{2}=0.71\right)$, with know appearing at significantly higher percentages in the form of first $(18 \%)$ and second person $(17 \%)$ compared with third person $(2 \% ; t(56)=8.77, p<0.001 ; t(56)=8.16, p<0.001$, respectively); ${ }^{2}$ see Fig. 2 . Similarly, a main effect of person was found for the verb remember $\left(F(2,106)=88.19, p<0.001\right.$, partial $\left.\eta^{2}=0.68\right)$, which appeared at significantly higher percentages in the form of second person (16\%) compared with first $(3 \% ; t(56)=-8.82, p<0.001)$, which, in turn, occurred a higher percentage of the time than third person $(0.2 \% ; t(56)=5.02, p<0.001) ;^{3}$ see Fig. 2 . 


\section{VOLUME 28 ISSUE 4}
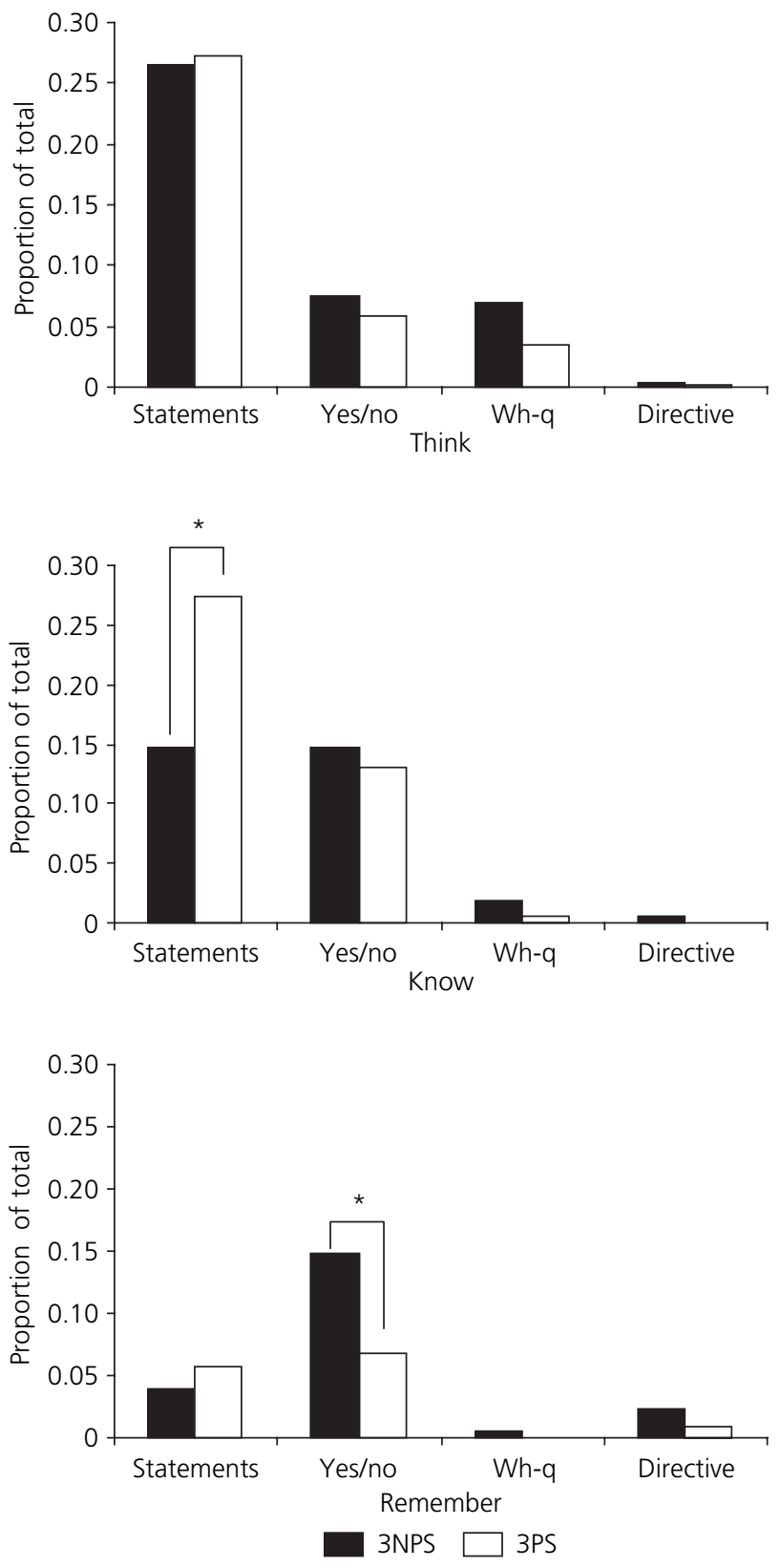

Figure 1 The proportion of wh-questions, yes/no-questions, statements and directives containing think, know and remember out of the total number of mental verb utterances 

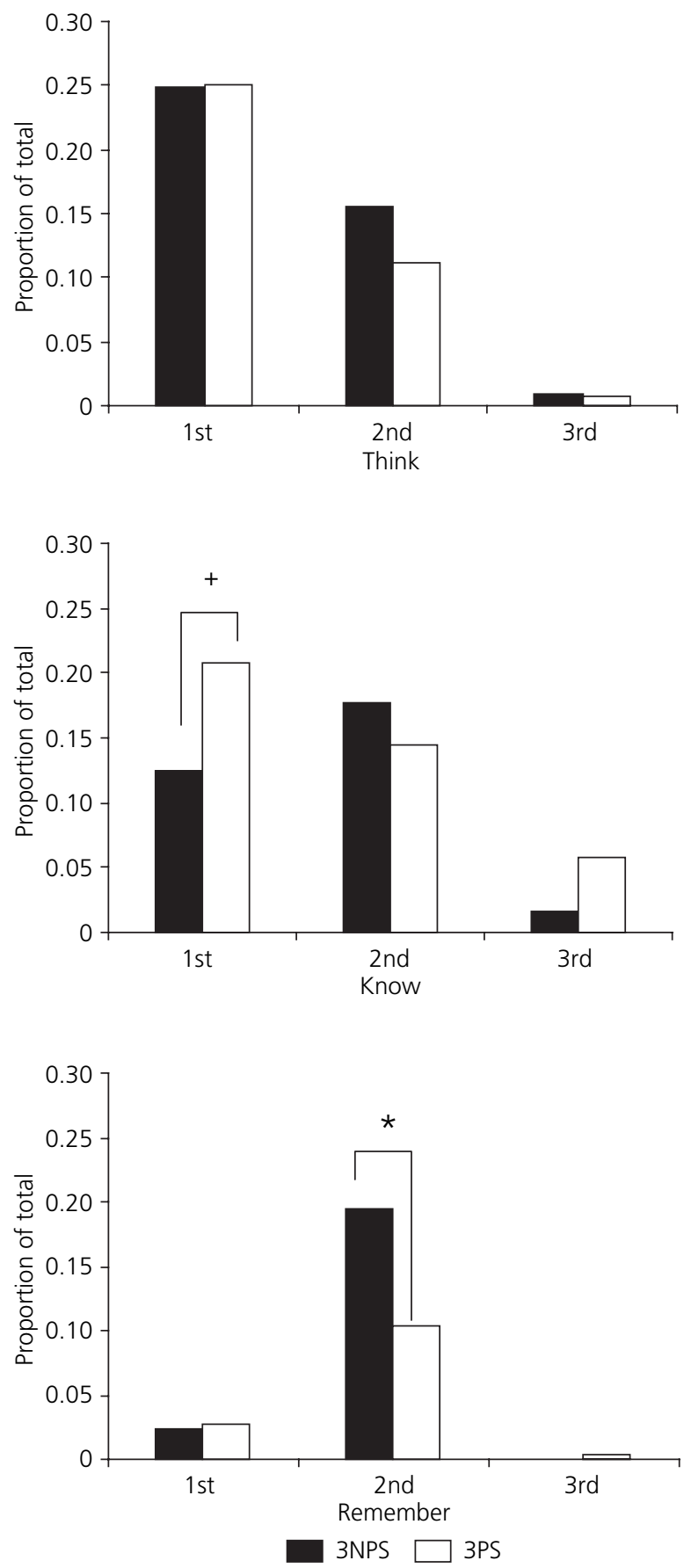

Figure 2 The proportion of first, second and third person utterances containing think, know and remember out of the total number of mental verb utterances ( + indicates $p<0.08$ ) 
Finally, we examined the group differences concerning the certainty of think statements using a non-parametric test (a test not affected by the fact that each group's certainty codings summed to $100 \%$ ). The percentages of 'very certain', 'certain', 'uncertain' and 'very uncertain' uses out of the total number of think statements are shown in Fig. 3. The modal use of think was its 'certain' form for all mothers; however, notice that 'very certain' uses comprised a greater percentage in the PS mothers compared with the NPS mothers ( $25 \%$ vs. $5 \%$ ). Indeed, a Mann-Whitney $U$ analysis revealed that PS mothers used think significantly more in its 'very certain' form than the NPS mothers $(U=46.0, p<0.05)$.

In sum, both think and remember occurred most commonly in the form of statements overall, while remember appeared most commonly as a yes/no-question. Moreover, two interactions were found with the preschool variable: the NPS children overall heard significantly higher percentages of yes/no-questions with remember compared with the PS children, and the three-year-old NPS children heard a smaller percentage of statements with know than the PS children of the same age. The majority of utterances with think, know and remember appeared with either a finite clause or no clause at all; very few subjunctives occurred. A higher percentage of think utterances were in the first person (e.g., 'I think the door is closed.'), whereas know utterances appeared at similar high rates in the first and second person (e.g., 'I know where it is.' and 'You know where to put it.'). A higher percentage of remember utterances were in the second person (e.g., 'Do you remember?'). The nonparametric analyses further revealed more specific verb, person, and utterance-type differences between the two groups of mothers of three-year-olds. ${ }^{1-4}$ Finally, the PS mothers used think significantly more often in its 'very certain' sense than the NPS mothers did (e.g., I think you should try and finish one game and then play with him).

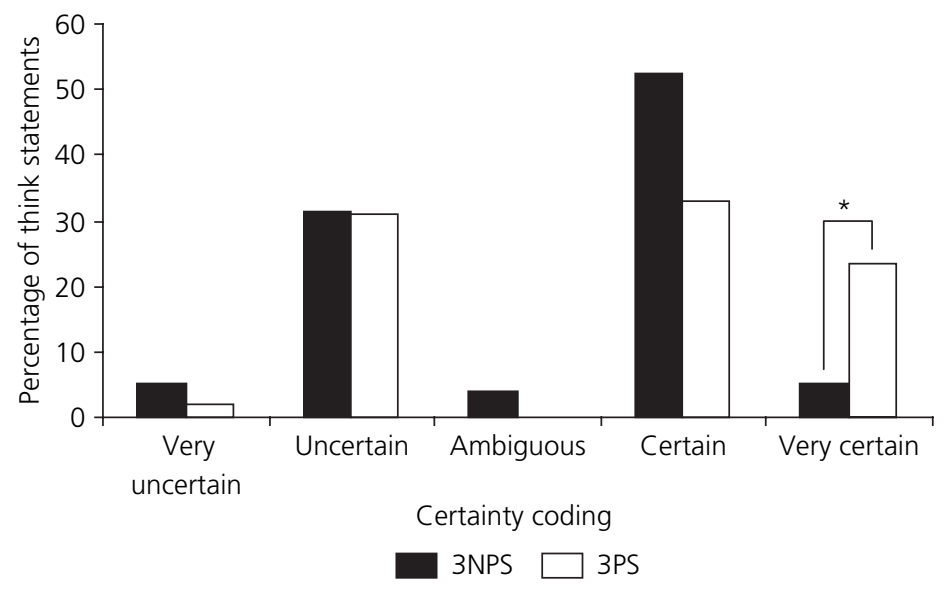

Figure 3 The percentage of certainty codings for think uses out of the total number of think statements 


\section{How maternal conversations predict child performance}

The next question of interest concerned the extent to which the variation in aspects of maternal conversations might account for individual differences in the children within and across groups. To investigate this, regression analyses were conducted. Due to the relatively small sample size, correlational analyses were employed to determine the maternal input variables that were significantly related to the child outcome variables before entering them into the regression model. This ensured that the case-to-independent-variable ratio remained as large as possible (Tabachnick \& Fidell, 2001). The correlation matrix for this study indicated that directives with think, wh-questions and statements with know, and know and remember utterances without a subordinate clause were all significantly related to children's outcome measures. Regression analyses were then performed using the significant maternal input variables as predictors to determine the amount of variance each contributed to the children's mental verb and false belief outcomes.

\section{Regressions}

Hierarchical regression, containing all 57 mother-child dyads (three- and four-yearolds), was used to examine the extent to which aspects of maternal conversations contribute to children's variance in their (a) mental verb scores and (b) false belief scores, over and above the children's age and language ability. The preschool variable ( 0 = NPS; $1=$ PS) was initially included in all the regression analyses; however, this variable did not significantly predict any of the child outcome variables. Therefore, it is not included in any of the reported findings.

Because no input variables significantly correlated with children's performance on the two mental verb tasks combined, the first regression analysis contained the children's score only on the puppet mental verb task as the dependent variable (see Table 6). The child's age was entered in years and months as a decimal conversion in Step 1 to control for the expected age effects. In Step 2, the raw total on the language comprehension measure (TACL-3) was entered to account for the effects of general language ability. Step 3 contained wh-questions with know, and step 4 contained statements with know. The final model was significant $(F(4,52)=4.21$, $p<0.01$ ) and explained $25 \%$ of the variance in mental verb understanding. Age, entered as the first variable, explained a significant amount of variance $(9 \%, \beta=$ $0.37, p<0.01)$. Interestingly, in step 2 , general language ability did not contribute significantly to the prediction of mental verb understanding. However, know utterances coded as wh-questions, entered in step 3, approached significance $(\beta=0.25$, $p<0.06)$. Finally, statements with know further explained $9 \%$ of the variance in children's performance on the mental verb understanding task; however, this variable negatively predicted children's performance $(\beta=-0.30, p<0.05$ ).

To further investigate this finding, and because the PS effect for know statements held only for first person, ${ }^{4}$ a second regression analysis was performed, using know statements in the first, second and third person as the predictors. Again, children's score on the puppet mental verb task was entered as the dependent variable. Age and language ability were again entered in steps 1 and 2. Steps 3-5 contained know statements in the third person, know statements in the second person and 
Table 6 Summary of hierarchical regression analysis for variables predicting performance on the puppet mental verb task $(N=57)$

\begin{tabular}{|c|c|c|c|c|c|}
\hline Step & Variable & $B$ & SE B & $b$ & $\Delta R^{2}$ \\
\hline \multicolumn{6}{|c|}{ Model 1} \\
\hline 1 & Age & 0.98 & 0.41 & $0.31 *$ & 0.09 \\
\hline \multirow[t]{2}{*}{2} & Age & 0.88 & 0.55 & 0.27 & \\
\hline & TACL-3 & 0.01 & 0.02 & 0.05 & 0.00 \\
\hline \multirow[t]{3}{*}{3} & Age & 0.90 & 0.54 & 0.28 & \\
\hline & TACL-3 & 0.00 & 0.02 & 0.04 & \\
\hline & Wh-q knowa & 16.32 & 8.17 & $0.25+$ & 0.06 \\
\hline \multirow[t]{4}{*}{4} & Age & 1.18 & 0.53 & $0.37^{*}$ & \\
\hline & TACL-3 & 0.00 & 0.02 & -0.01 & \\
\hline & Wh-q know & 15.30 & 7.82 & $0.24+$ & \\
\hline & Statement know & -4.24 & 1.73 & $-0.30^{*}$ & 0.09 \\
\hline \multicolumn{6}{|c|}{ Model II } \\
\hline 1 & Age & 0.98 & 0.41 & $0.31^{*}$ & 0.09 \\
\hline \multirow[t]{2}{*}{2} & Age & 0.88 & 0.55 & 0.27 & \\
\hline & TACL-3 & 0.01 & 0.02 & 0.05 & 0.00 \\
\hline \multirow[t]{3}{*}{3} & Age & 1.08 & 0.54 & $0.34^{*}$ & \\
\hline & TACL-3 & 0.00 & 0.02 & 0.00 & \\
\hline & 3rd per. $\mathrm{K} \mathrm{st}^{\mathrm{C}}$ & -0.455 & 4.59 & -0.13 & 0.02 \\
\hline \multirow[t]{4}{*}{4} & Age & 0.97 & 0.57 & 0.30 & \\
\hline & TACL-3 & 0.00 & 0.02 & 0.00 & \\
\hline & 3rd per.K st & -4.52 & 4.59 & -0.13 & \\
\hline & 2nd per.K st ${ }^{d}$ & 6.61 & 6.75 & 0.14 & 0.02 \\
\hline \multirow[t]{5}{*}{5} & Age & 0.97 & 0.57 & 0.30 & \\
\hline & TACL-3 & 0.00 & 0.02 & -0.01 & \\
\hline & 3rd per.K st & -5.58 & 4.41 & -0.16 & \\
\hline & 2nd per.K st & 3.86 & 6.56 & 0.08 & \\
\hline & 1 st per. $\mathrm{K} \mathrm{st}^{\mathrm{e}}$ & -4.54 & 1.89 & $-0.31^{*}$ & 0.09 \\
\hline
\end{tabular}

$+p<0.06 ;{ }^{*} p<0.05$.

a know utterances coded as wh-questions; ${ }^{b}$ know utterances coded as statements; ${ }^{c}$ third person know statements; ${ }^{d}$ second person know statements; ${ }^{e}$ first person know statements.

know statements in the first person (see Model II of Table 6). Of the three variables, know statements in the first person are the only type of utterance to significantly (negatively) predict children's mental verb understanding $(\beta=-0.31, p<0.05)$.

For the regression analysis predicting children's false belief performance, children's total false belief score (0-4) was entered as the dependent variable (see Table 7). Age was entered as a control in step 1, while children's raw score on the TACL-3 was again entered in step 2 . The remaining predictors were based on significant pairwise correlations and included know utterances without a subordinate clause (entered in 
step 3), directives with think (entered in step 4), remember utterances without a subordinate clause (entered in step 5) and remember statements (entered in step 6). The model was significant $(F(6,50)=7.34, p<0.001)$ and explained $47 \%$ of variance in the false belief scores. Age, entered in step 1, explained $18 \%$ of the variance $(\beta=0.43, p<0.01)$. Children's performance on the TACL-3 accounted for $10 \%$ of the variance $(\beta=0.42, p<0.01)$. Above age and language ability, know utterances without a subordinate clause significantly predicted $6 \%$ of the variance $(\beta=0.25$, $p<0.05)$. Although think directives in the next step did not contribute significantly to the model, remember utterances without a subordinate clause explained $9 \%$ of the variance in children's false belief performance $(\beta=0.31, p<0.01)$. And finally, remember statements did not contribute significantly to the model. However, it is important to note that if remember statements are entered in the step before remember utterances without a subordinate clause, then they do contribute significantly to the model $(\beta=0.25, p<0.05)$. Moreover, when remember utterances without a subordinate clause are entered in the last step, the contribution to the model is not as strong $(\beta=0.26, p<0.055)$.

\section{DISCUSSION}

The purpose of this study was to investigate how maternal uses of mental verbs in conversation with their children might relate to those children's developing abilities to distinguish between mental verbs and to acquire a theory of mind. The children's performance on the MV and false belief tasks was consistent with previous findings in the literature. That is, the four-year-olds performed above chance on both mental verb and false belief tasks, and significantly better than the three-year-olds, who performed at chance (see also Moore et al., 1989; Wellman, 1990). Moreover, the children's performance on the MV and false belief tasks was intercorrelated (see also Brown et al., 1996; Moore et al., 1990), as was their performance on these tasks and their general language ability (see also Astington, 2000). Importantly for our desire to study a sample with considerable variance, we also found that within the three-year-old group, those who attended preschool performed less well on the puppet mental verb task than those who did not attend preschool. Thus, our child participants performed as expected, and generated enough variance to support expectations of differences among their mothers in mental verb use. However, it is important to note, that although the preschool status of the children created variance in both child outcomes and maternal speech, preschool status itself did not predict any variance in children's outcome measures. It is possible that the fairly wide range of PS experiences in our sample (i.e., 3 to 40 hours/week) might have yielded a less coherent group of children (e.g., NICHD Early Child Care Research Network, 2000, 2007).

Our next four findings related more directly to our primary purpose, which concerned the type of maternal mental verb input that may be related to children's understanding of the mental world. First, group comparisons and regression analyses demonstrated that questions were facilitative whereas statements were inhibitory with respect to learning mental verb distinctions. These findings support 
Table 7 Table summary of hierarchical regression analysis for variables predicting false belief performance $(N=57)$

\begin{tabular}{|c|c|c|c|c|c|}
\hline Step & Variable & $B$ & SE B & $\beta$ & $\Delta R^{2}$ \\
\hline 1 & Age & 0.99 & 0.29 & $0.43^{* *}$ & 0.18 \\
\hline \multirow[t]{2}{*}{2} & Age & 0.35 & 0.36 & 0.15 & \\
\hline & TACL-3 & 0.03 & 0.01 & $0.42 * *$ & 0.10 \\
\hline \multirow[t]{3}{*}{3} & Age & 0.32 & 0.35 & 0.14 & \\
\hline & TACL-3 & 0.03 & 0.01 & $0.40^{*}$ & \\
\hline & NoCl knowa & 2.80 & 1.28 & $0.25^{*}$ & 0.06 \\
\hline \multirow[t]{4}{*}{4} & Age & 0.41 & 0.34 & 0.18 & \\
\hline & TACL-3 & 0.02 & 0.01 & $0.35^{*}$ & \\
\hline & NoCl know & 2.47 & 1.27 & $0.22^{+}$ & \\
\hline & Directive $\mathrm{T}^{\mathrm{b}}$ & -25.73 & 14.86 & -0.20 & 0.04 \\
\hline \multirow[t]{5}{*}{5} & Age & 0.10 & 0.34 & 0.04 & \\
\hline & TACL-3 & 0.03 & 0.01 & $0.46^{* *}$ & \\
\hline & NoCl know & 2.83 & 1.20 & $0.25^{*}$ & \\
\hline & Directive $T$ & -25.52 & 13.94 & -0.20 & \\
\hline & $\mathrm{NoCl}$ rememberc & 5.60 & 1.97 & $0.31 * *$ & \\
\hline \multirow[t]{6}{*}{6} & Age & 0.02 & 0.36 & 0.01 & \\
\hline & TACL-3 & 0.03 & 0.01 & $0.47^{* *}$ & \\
\hline & NoCl know & 2.93 & 1.21 & $0.26^{*}$ & \\
\hline & Directive $\mathrm{T}^{\mathrm{b}}$ & -24.11 & 14.14 & -0.19 & \\
\hline & $\mathrm{NoCl}$ remember ${ }^{\mathrm{c}}$ & 4.67 & 2.36 & $0.26^{+}$ & \\
\hline & Statement $R^{d}$ & 1.49 & 2.06 & 0.10 & 0.01 \\
\hline
\end{tabular}

${ }^{+} p<0.06 ;{ }^{*} p<0.05 ;{ }^{*} p<0.01$

${ }^{a}$ know utterances without a subordinate clause; ${ }^{b}$ think directives; ${ }^{c}$ remember utterance without a subordinate clause; ${ }^{\mathrm{d}}$ remember statements

those of Adrian et al. (2007), who also found facilitatory effects for maternal questions. They do not support a positive role for statements, contrary to Slaughter et al.'s (2007) findings; however, Slaughter et al. reported a positive role only for a very specific type of statement (cognitive clarifications). We conjecture that questions containing mental verbs are facilitative because they bring children's attention to specific meanings, namely, their own mentation. For example, a mother who asks her child 'What do you know about this game?' is explicitly drawing the child's attention to his/her own mental experience, and providing labels to help to distinguish different aspects of that mental experience, and thus helping distinguish the mental verbs.

Second, one of the strongest findings, evident in both the group comparisons and the regression, is that the use of mental verbs in reference to others rather than oneself facilitates children's acquisition of distinctions between mental verbs. These findings corroborate and extend those of Booth et al. (1997); moreover, because our 
child measures were drawn independently from the maternal conversations, the relation between the two cannot be attributable to priming, or to topic choices that elicit specific verb uses from the child. Instead, it seems likely that mothers who talk more about the mental states of others facilitate their children's understanding of the different perspectives that different people might have - themselves included. These findings corroborate those of Adrian et al. (2007) and help to refine the theoretical stance of Dunn \& Brophy (2005; see also Harris, 2005; Montgomery, 2002), that maternal conversations enable the introduction of different points of view. Specifically, this seems to be accomplished by conversations that explicitly discuss the mental states of others. The link from such different perspectives to distinctions between mental verbs is not yet fully elaborated, however, because reference to others' mental states does not mandate the use of different verbs. Perhaps, though, children who hear more about the mental states of others become more quickly attuned to the ways these mental states are described - primarily, by different verbs. On this account, different person forms used in maternal conversations may draw children's attention to the fact that verb meanings differ, but are not necessarily revealing about what the actual semantic differences are.

Our third major finding concerns the importance of know and remember in single-clause utterances, regardless of type. The fact that remember emerged as a positive predictor in the false belief regression may be partly attributable to the fact that the majority of these utterances (55-70\% across groups) were indeed questions (e.g., 'Do you remember the card?'). Mothers who ask their children more about their own remembering may be stimulating the children to reflect on those mental processes, bringing them closer to conscious awareness and highlighting how they differ in different situations. However, there are two hedges: (1) remember statements contribute similar amounts of variance as single clause remember utterances, and (2) fewer single-clause know utterances were questions (27-29\% across groups). Therefore, another reason that these utterances may have emerged as positive predictors is that because they are single-clause utterances, they are short and simple. As a consequence, children need not spend time processing the subordinate clause of the sentence; they can instead focus on the mental aspect of the sentence (e.g., 'You know that', 'You have to remember').

The one aspect of maternal conversation that could directly relate to children's good performance on the mental verb tasks is the proportion of 'very certain' uses of think (e.g., 'I think you've had enough peas for now'). Naigles (2000) had conjectured that mothers who used think more in its 'comment' sense, while perfectly appropriate, were providing multiple instances of how think could be used similarly to know, rather than as less certain than know. In support, we found that think in its 'very certain' sense was more common in the maternal input of the PS children, whose performance on the puppet mental verb task was lower than that of the NPS children. However, this relationship between 'very certain' uses and outcome performance held only for the group analyses. In other words, percentage of 'very certain' uses was not significantly related to children's performance on the puppet mental verb task, or any other output measures.

Therefore, children do seem to have a clear understanding of the meaning of think (and thus the certainty of think) to perform well on the puppet task. But it is 
also possible that children need only hear some relatively small proportion of think uses in their 'canonical' uncertain sense to reach some threshold of realization such that when mental verbs are contrasted (as in our mental verb tasks), the point of contrast is presumed to be the level of certainty. This possibility could be further explored with an experimental manipulation.

Taken together, our detailed examination of the way(s) mothers used mental verbs in conversation has proved to be quite fruitful, discovering positive effects of questions, reference to others and level of certainty. Only the subjunctive clauses yielded no effects; however, these were also extremely rare in our dataset, either because they are rare overall in maternal conversations or because we did not record the types of situations in which subjunctive clauses might be heard.

Three other findings from the study, while not central to its goals, are also worthy of some discussion. First, why were the mothers who did not send their three-year-old children to preschool the ones who used mental verbs in more ways that seemed facilitative of their acquisition? This 'nonpreschool' effect cannot be attributed to SES because both groups were primarily college-educated. Moreover, the findings from the literature related to preschool attendance have generally found that it is children who do attend preschool who perform better and/or have more engaged and didactic parents (e.g., Naigles, 2000; NICHD Early Child Care Research Network, 2007; Rogoff et al., 1991; Vinden, 2002). We conjecture that within the middle-to-upper SES bracket, mothers of three- and four-year-olds exercise a deliberate choice, either to send their children to preschool, with all its attendant cognitive and social benefits, or to keep them at home, with the mothers themselves providing the benefits. Thus, mothers of three-year-olds who do not send their children to preschool may deliberately focus their conversations on the types of didactic interaction that they assume children who go to preschool are possibly receiving from their teachers.

Second, why were so few environmental influences (i.e., from maternal conversations) seen with the four-year-olds compared with the three-year-olds? While the four-year-olds did not perform perfectly on the tasks, their performance was consistently above chance. Therefore, because most of the fouryear-olds were demonstrating some understanding of mental states, the variance in the type of maternal mental verb speech might not be as high as in the threeyear-olds. In other words, the way in which mothers use mental state verbs might be influenced not only by the child's mental state speech, but by the child's mental state understanding. Therefore, mothers of three-year-olds might be more sensitive to what their child is understanding (or not) and adjust their speech accordingly (e.g., more questions than statements), whereas mothers of four-yearolds need not make such adjustments. Similarly, another possibility is that the aspects of maternal conversation we examined are those that are most relevant earlier in development. Questions, references to others, and using think less in its 'very certain' sense may help three-year-olds because they are currently engaged in learning how people have different perspectives, how they can reflect on their own mental states and how degrees of certainty are mapped onto the verbs think, guess and know. Further developments in MV understanding and ToM (e.g., Booth and Hall, 1995) may be attributable to different aspects of maternal conversations. 
Thus, it seems that at least some of the facilitating aspects of maternal conversations that we have examined are important properties of the input of less rather than more advanced children. A further possibility as to why we found preschool difference among the three-year-olds but not the four-year-olds could be attributable to something inherently different about mothers who choose not to send their children to preschool when they are four versus three years of age. However, a more detailed study would better distinguish what these differing parenting philosophies might be.

Therefore, the limitations of the study include the absence of younger children (i.e., children two years of age), as well as the use of a cross-sectional rather than longitudinal design. A longitudinal design including a greater age range would have allowed for more detailed analyses of the children's mental verb production in relation to the maternal input, because the utterances for the mother and child would not have been drawn from the same conversation. Moreover, a longitudinal design would have enabled analyses revealing how earlier maternal conversations actually influence subsequent child mental verb use. Finally, if more children overall had been included, then separate regression analyses could have been conducted for each age group, making it possible to examine whether different aspects of conversations are more important in predicting children's mental verb and false belief performance, depending on the age of the child.

In sum, these findings provide a more detailed account of just how maternal conversations may be informative for children learning about mental verbs and false beliefs. Importantly, we did not find one overarching aspect that could serve as the 'key' to children's developments at this age, but rather have highlighted a compilation of forms and senses that may each provide smaller pieces to the big picture (i.e., more questions, more second person utterances - especially short ones - with remember, fewer very certain forms with think). Future directions might include experimental manipulations of some of these pieces, as well as further scrutiny of maternal conversations to discover other aspects that contribute to later developments in children's understanding of the mental world.

\section{NOTES}

1. Among the three-year-olds, the NPS mothers used a higher percentage of yes/no-questions containing remember than the PS mothers did $(U=46.5, p<0.05)$.

2. The PS mothers of three-year-olds tended to use a higher percentage of first person know utterances than the NPS mothers did $(U=64, p<0.08)$.

3. The NPS mothers of three-year-olds used a significantly higher percentage of remember utterances in the second person than the PS mothers did $(U=55.5, p<0.05)$.

4. Pairwise Mann-Whitney Us also compared person effects by specific utterance types. The PS mothers of three-year-olds tended to use a higher percentage of know statements in the first person compared with the NPS children (Ms $=21 \%$ and $12 \%$, respectively; $U=60.5, p<0.06$ ), whereas, the NPS mothers used a higher percentage of yes/no-questions in the second person with remember than the PS mothers did (Ms $=15 \%$ and $7 \%$, respectively; $U=46.50, p<0.05)$. No other person differences at the utterance type level were found. 


\section{REFERENCES}

Adrian, J., Clemente, R. A. \& Villanueva, L. (2007). Mothers' use of cognitive state verbs in picture-book reading and the development of children's understanding of mind: A longitudinal study. Child Development, 78, 1037-1404.

Astington, J. W. (2000). Language and metalanguage in children's understanding of mind. In J. W. Astington (Ed.), Minds in the making: Essays in honor of David R. Olson (pp.267-284). Malden, MA: Blackwell Publishers.

Astington, J. \& Baird, J. (2005). Why language matters for theory of mind. New York: Oxford University Press.

Bartsch, K. \& Wellman, H. (1995). Children talk about the mind. New York: Oxford University Press.

Beeghly, M., Bretherton, I. \& Mervis, C. (1986). Mothers' internal state language to toddlers. British Journal of Developmental Psychology, 4, 247-261.

Booth, J. \& Hall, W. (1995). Development of the understanding of the polysemous meanings of the mental state verb know. Cognitive Development, 10, 529-549.

Booth, J., Hall, W., Robison, G. \& Kim, S. (1997). Acquisition of the mental state verb know by 2- to 5-year-old children. Journal of Psycholinguistic Research, 26, 581-603.

Brown, J., Donelan-McCall, N. \& Dunn, J. (1996). Why talk about mental states? The significance of children's conversations with friends, siblings, and mothers. Child Development, 67, 836-849.

Brown, J. \& Dunn, J. (1991). 'You can cry mum.': The social and developmental implications of talk about internal states. Journal of Developmental Psychology, 9(2), 237-256.

Carrow-Woolfolk, E. (1999). Test for Auditory Comprehension of Language-Third Edition. Circle Pines, MN: AGS.

deVilliers, J. (2005). Can language acquisition give children a point of view? In Astington \& Baird, 2005: 186-219.

deVilliers, P. (2005). The role of language in theory of mind development: What deaf children tell us. In Astington \& Baird, 2005: 266-297.

Dunn, J. \& Brophy, M. (2005). Communication, relationships, and individual differences in children's understanding of mind. In Astington \& Baird, 2005: 50-69.

Dunn, J. \& Brown, J. (1991). Becoming American or English? Talking about the social world in England and the United States. In M. Bornstein (Ed.), Cultural approaches to parenting (pp. 155-172). Hillsdale, NJ: Erlbaum.

Frank, R. \& Hall, W. (1991). Polysemy and the acquisition of the cognitive internal state lexicon. Journal of Psycholinguistic Research, 20, 283-304.

Furrow, D., Moore, C., Davidge, J. \& Chiasson, L. (1992). Mental terms in mothers' and children's speech: Similarities and relationships. Journal of Child Language, 19, 617-631.

Gleitman, L. (1990). The structural sources of verb meanings. Language Acquisition, 1, 3-55.

Gleitman, L., Cassidy, K. \& Nappa, R. (2005). Hard words. Language Learning and Development, 1, 23-64.

Gravetter, F. \& Wallnau, L. (2004). Statistics for the behavioral sciences (6th ed.). Belmont, CA: Thomas Learning.

Hale, C. \& Tager-Flusberg, H. (2005). Social communication in children with autism: The relationship between theory of mind and discourse development. Autism, 9, 157-178.

Harris, P. (2005). Conversation, pretense, and theory of mind. In Astington \& Baird, 2005: 70-83.

Hohenstein, J., Naigles, L. \& Marsland, K. (1998). How input might facilitate the acquisition of mental state verbs: A comparison of mothers and preschool teachers. Paper presented at Jean Piaget Society, Chicago, June. 
Hollingshead, A. (1971). Commentary on the 'indiscriminate state of social class measurement'. Social Forces, 49, 563-567.

Jenkins, M., Turrell, S., Kogushi, Y., Lollis, S. \& Ross, H. (2003). A longitudinal investigation of the dynamics of mental state talk in families. Child Development, 74, 905-920.

Lohmann, H., Tomasello, M. \& Meyer, S. (2005). Linguistic communication and social understanding. In Astington \& Baird, 2005: 245-265.

MacWhinney, B. \& Snow, C. (1985). The Child Language Data Exchange System. Journal of Child Language, 12, 271-295.

Manson, N. (1995). What does language tell us about consciousness? First-person mental discourse and higher-order thought theories of consciousness. Philosophical Psychology, $15,221-238$.

Montgomery, D. (2002). Mental verbs and semantic development. Journal of Cognition and Development, 3, 357-384.

Moore, C., Bryant, D. \& Furrow, D. (1989). Mental terms and the development of certainty. Child Development, 49, 1107-1113.

Moore, C. \& Davidge, J. (1989). The development of mental terms: Pragmatics or semantics? Journal of Child Language, 16, 633-641.

Moore, C., Furrow, D., Chiasson, L. \& Patriquin, M. (1994). Developmental relationships. Between production and comprehension of mental terms. First Language, 14, 1-17.

Moore, C., Pure, K. \& Furrow, D. (1990). Children's understanding of the modal expression of speaker certainty and uncertainty and its relation to the development of representational theory of mind. Child Development, 61, 722-730.

Naigles, L. (2000). Manipulating the input: Studies in mental verb acquisition. In B. Landau \& Sabini et al. (Eds), Perception, cognition, and language: Essays in honor of Henry and Lila Gleitman (pp.245-274). Cambridge, MA: MIT Press.

NICHD Early Child Care Research Network (2000). The relation of child care to cognitive and language development. Child Development, 71, 960-980.

NICHD Early Child Care Research Network (2007). Child Care and Child Development. New York: Guilford Press.

Perner, J., Leekam, S. R. \& Wimmer, H. (1987). Three-year-olds' difficulty with false belief. British Journal of Developmental Psychology, 5, 125-137.

Rogoff, B., Mistry, J., Goncu, A. \& Mosier, C. (1991). Cultural variation in the role relations of toddlers and their families. In M. Bornstein (Ed.), Cultural approaches to parenting (pp. 173-184). Hillsdale, NJ: Erlbaum.

Ruffman, T., Slade, L. \& Crowe, E. (2002). The relation between children's and mothers' mental state language and theory of mind understanding. Child Development, 73, 734-751.

Schwanenflugel, P., Fabricius, W. \& Noyes, C. (1996). Developing organization of mental verbs: Evidence for the development of a constructivist theory of mind in middle childhood. Cognitive Development, 11, 265-294.

Shatz, M., Diesendruck, G., Martinez-Beck, I. \& Akar, D. (2003). The influence of language and socioeconomic status on children's understanding of false belief. Developmental Psychology 39, 717-729.

Shatz, M., Wellman, H. \& Silber, S. (1983). The acquisition of mental verbs: A systematic investigation of the first reference to mental state. Cognition, 14, 301-321.

Shatz, M. \& Wilcox, S. (1991). Constraints on the acquisition of English modals. In S. Gelman \& J. Byrnes (Eds), Perspectives on language and thought (pp. 319-353). Cambridge: Cambridge University Press.

Slaughter, V., Peterson, C. \& Mackintosh, E. (2007). Mind what mother says: Narrative input and theory of mind in typical children and those on the autism spectrum. Child Development, 78, 705-722. 
Tabachnick, B. \& Fidell, L. (2001). Using multivariate statistics. Boston, MA: Allyn and Bacon. Tager-Flusberg, H. (2000). Language and understanding minds: Connections in autism.

In S. Baron-Cohen, H. Tager-Flusberg \& D. J. Cohen (Eds), Understanding other minds: Perspectives from developmental cognitive neuroscience (2nd ed.) (pp. 129-154). Oxford: Oxford University Press.

Tardif, T. \& Wellman, H. (2000). Acquisition of mental state language in Mandarin- and Cantonese-speaking children. Developmental Psychology, 36, 25-43.

Urmson, J. (1952). Parenthetical verbs. In C. Caton (Ed.), Philosophy and ordinary language. (pp. 220-240). Urbana: University of Illinois Press.

Vinden, P. (2002). Understanding minds and evidence for belief: A study of Mofu children in Cameroon. International Journal of Behavioral Development, 26, 445-452.

Wellman, H. (1990). The child's theory of mind. Cambridge, MA: The MIT Press.

Wimmer, H. \& Perner, J. (1983). Beliefs about beliefs: Representation and constraining function of wrong beliefs in young children's understanding of deception. Cognition, $13,103-128$.

\section{ADDRESS FOR CORRESPONDENCE}

Dr Alice Ann Howard

Dept. of Psychology, University of Connecticut, 406 Babbidge Road, Unit 1020, Storrs, CT 06269, USA

E: aliceann.howard@gmail.com 